\title{
Discrete Hopfield Neural Networks for Evaluating Service Quality of Public Transit
}

\author{
Jinxing Shen ${ }^{1}$ and Wenquan $\mathrm{Li}^{2}$ \\ Transportation College, Southeast University, 2, Sipailou, Nanjing, 210096, China \\ ${ }^{1}$ shenjx03@163.com, ${ }^{2}$ wenqli@seu.edu.cn
}

\begin{abstract}
In this paper, we present Discrete Hopfield neural networks (DHNN) for evaluation service quality of public transit. First, we proposed an ideal service quality evaluation index system of public transit. Then, the survey conducted as a support to the study was realized in the winter of 2012 from Oct 8 to Oct 15 in the city of Nanjing. At Mast, the validity of the proposed methodology has been confirmed by the experinental results of 5 bus routes chosen at random. The results show that it is essential to capture more detailed information about service quality of public transit from passenger perceptions with DHNN.
\end{abstract}

Keywords: Discrete Hopfield neural networks; service quadity; public transit

\section{Introduction}

During the past decade, publictransit is suffering the competitive pressure from the private traveling tools in worldwide The personal freedom offered by the car, which has enhanced the rise in car ownership, which has in turn encouraged even greater car use because access is not as easily available by public transit [1,2]. So, a major concern in public transit today is to continue to improve the service quality and improve the attractiveness to people. Service quality is a copmparison of expectations with performance that is focused both in academic research and in public and prizate service. The measurement of service quality continues to be a challenging research theme and one of great practical importance to service providers and regulatory agencies [3. Specifically in public transport, "service quality" is an even more complex concept thanmust reflect a transit user's perspective and must measure how a transit route, service, facility, or system is operating under various demand, supply, and control conditions [4] The preferences for transit service quality are of great importance to transit service providers and socio-economic and so on $[5,6,7,8]$. However, we know relatively little about the quantitative criteria of the service quality of public transit [9].

For these reasons, plenty of efforts have been made by various researchers for measuring service quality and on the purpose of enhancing the service quality of public transit. Laura Eboli et al. develop a Stated Preference (SP) experiment that provides a way to measure service quality in public transport [10]. Mairead Cantwell et al. use a multinomial logit model to examine the factors that impact public transit [11]. Snežana Filipović et al. give a comparative analysis of the basic features of the expected and perceived quality of mass passenger public transport service in Belgrade [12]. Laura Eboli and Gabriella Mazzulla propose an index based on customer perspective for evaluating transit service quality [13]. David A. Hensher et al. investigates the role that enhanced service quality introduced into a deregulated market has in improving the experience of bus travel by a sample of passengers in the Tyne and Wear area of England [14]. Luigi dell'Olio et al. evaluates how bus users perceive the quality of their public transport service. In particular it looks at how perception 
of quality varies according to the available information [15]. In order to capture the passengers' point of view on a transit service, Laura Eboli and Gabriella Mazzulia introduce some discrete choice logit models to calculate the probability of choice of some alternative transit services and to determine the importance of each service aspect [16]. Francois Des Rosiers et al. suggest that increasing regular bus frequencies results, by and large, in lower house values for properties located in the vicinity of regular routes; and the reverse is true for Express lines, which exert a substantial, positive influence on prices. Thus, by offering a more direct and efficient (fewer stops) as well as more comfortable mode than both the regular and Metrobus services, the Express actually proves to be a convenient substitute to the private car for suburban homeowners with a regular working schedule[17]. Cinzia Cirillo et॰al. investigate the heterogeneity of transit users in perceiving service quality through a mixed logit model with a non-parametric distribution of the coefficients [18]. Jiangping Z hou and Lisa Schweitzer examines employees' participation in a free and discounted try-transit program called "Dump the Pump" (DtP) in Los Angeles, California. They think, public transit would be attractive to employees or employee drivers only when their individual concerns are well addressed and when riding public transit provides them with comparable overall utilities to driving [19]. Wentai Lai and Chingfu Chen investigate public transit passengers' behaviors by constructing a comprehensive model value, satisfaction, and behavioral intentions [20]. Laura Eboli and Gabriella Mazzulla proposed a methodoløgy for evaluating transit service quality based on the passenger perceptions and transit agency performance [21]. Nir Sharaby and YoramShiftan evaluate the impact of fare integration on transit ridership and travel behavior [22]. Marta Rojo et al. propose a medel for analyzing the relationship between service quality and modal choice of ravelers making inter-urban journeys [23]. Juan de Oña et al. present a classification tree dpproach to identify key factors of transit service quality [24]. Two non-parametric tree based (CART) models were proposed to study which variables played a more important role in the pepception of SQ by PT passengers in the Metropolitan Area of Granada. They find out that passengers' perceived quality of service is practically limited to frequency speed and punetuality in the preliminary evaluation.

The measurement of service quality of public transit has been, and will continue to be, an important study focus among competing transit agencies. Although a lot of effort is being spent on improving the service quality of public transit, the efficient and effective method that could evaluate the service quality of different bus lines has yet to be developed.

In this paper, we present Discrete Hopfield neural networks (DHNN) for evaluation of service quality of public transit. For this purpose, Section 2 proposes the requirement assumptions and the applications of Discrete Hopfield neural networks. Section 3 presents the solution approach for evaluating service quality of public transit. In Section 4, we analyze and discuss the collected data from the questionnaire survey and present an application of our approach on evaluation of service quality for public transit in Nanjing, China. Conclusions and problems that remain to be solved are given in Section 5. The acknowledgments are located in the final section.

\section{Discrete Hopfield neural networks (DHNN)}

DHNN is a form of recurrent artificial neural network invented by John Hopfield [25]. DHNN serve as content-addressable memory systems with binary threshold nodes. They are guaranteed to converge to a local minimum, but convergence to a false pattern (wrong local minimum) rather than the stored pattern (expected local minimum) can occur. Some related definitions of DHNN adapted from [26, 27, 28, 29] are presented as follows. 


\subsection{Network structure}

The units in DHNN are binary threshold units. That is to say, the units only take on two different values for their states. The value is determined only by whether or not the units' input exceeds their threshold. In this paper, we assumption the values of the units is 1 or -1 . The network structure could be described in Figure 1.

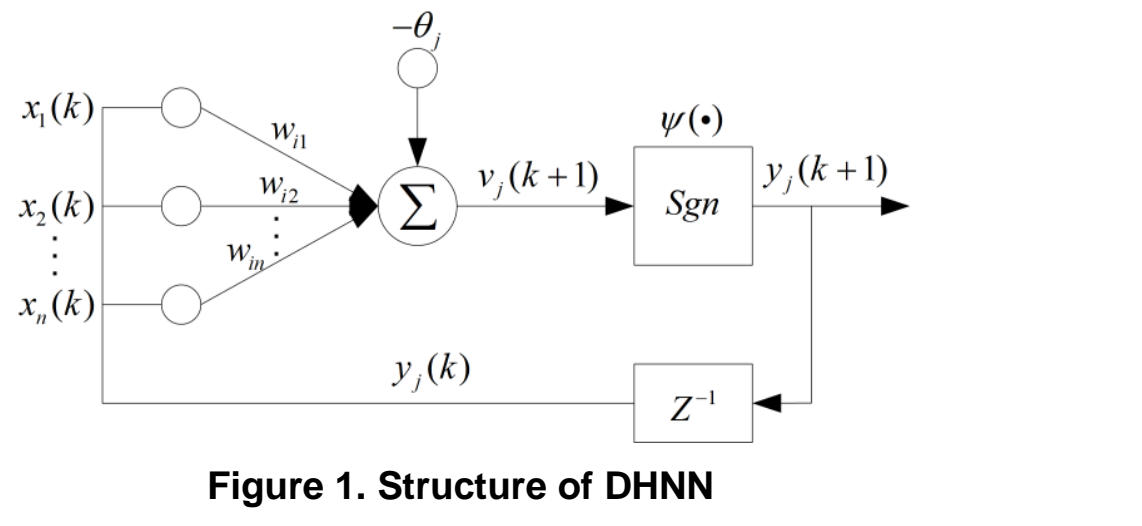

In Figure 1, the actions of DHNN could be illustrated as:

Where:

$$
y_{\dot{C}}(R+1)=\psi\left[\sum_{j=1}^{n} m_{j} l_{j}(k)-\theta_{j}\right]
$$

$n$ is the number of inpu-heurons;

$x_{j}$ is input neurons in this paper, the value is 1 or -1 ;

$w_{i j}$ is the comection weight between units $x_{i}$ and $x_{j}$, in this paper we assume $w_{i j}=w_{j i}$ and $w_{i i} \neq 0$;

$\theta_{j}$ is an externally applied threshold of unit $x_{j}$;

$k$ is the discrete time;

$\psi(\square)$ is the Sign function, that is to say, in this paper the units use a bipolar output function where the states of the units is 1 or 0 . We assume:

$$
\psi(\tau)=\left\{\begin{array}{l}
1, \tau \geq 0 \\
-1, \tau<0
\end{array}\right.
$$

$Z^{-1}$ is the unit delay, means $y_{j}(k+1)=\psi\left[v_{j}(k+1)\right]$, where,

$$
\left\{\begin{array}{l}
v_{j}(k)=v_{j}\left(k T_{s}\right) \\
v_{j}(k+1)=\sum_{j=1}^{n} w_{i j} x_{j}(k)-\theta_{j}
\end{array}\right.
$$

$T_{s}$ is the sampling period, in general, the sample period is normalized to unity, means $T_{s}=1$; 


\subsection{Network updating}

Updating one unit (node in the graph simulating the artificial neuron) in DHNN is performed using the following rule:

Ruler 1: The network is updated asynchronously, in this condition, only one neuron $x_{j}$ is selected at time $k+1$. This unit could be chosen at random, or a predefined order can be imposed from the very beginning. The updating rule could be described as:

$$
x_{j}(k+1)=\psi\left[v_{j}(t)\right]=\left\{\begin{array}{l}
1, v_{j} \geq 0 \\
-1, v_{j}<0
\end{array}\right.
$$

Ruler 2: The network is updated synchronously, that is to say, there are $\operatorname{ma}(1<m \leq n)$ neurons are selected at time $k+1$. The updating rule could be described as.

$$
x_{j}(k+1)=\psi\left[v_{j}(t)\right],(j=1,2, . ., m)
$$

In this condition, a central clock is required to the system in order to maintain the network synchronization. So, Ruler 2 is less realistig, since there) lack a global clock in biological or physical systems that keeps track of time.

Network update will be ongoing until the network reaches a steady state. And the steady state of DHNN could be described as.

\subsection{Stability of the network}

$$
\left.x_{i}(k+D)=x_{i}(k)=\psi\left(v_{i}, k\right)\right), i=1,2, \ldots, n
$$

The stability of DHNNeguld be demonstrated by an energy function as:

$$
E_{\mathrm{P} H N N}=-\frac{1}{2} \sum_{i=1}^{n} \sum_{j=1}^{n} w_{i j} x_{i} x_{j}+\sum_{i=1}^{n} \theta_{i} x_{i}
$$

It could be expressed in a matrix form as:

$$
E_{D H N N}=-\frac{1}{2} X^{T} W X+X^{T} \theta
$$

The units $x_{i}(i=1,2, n)$ of DHNN only take on two different values for their states; it is 1 or $-1 . \theta_{i}$ is the threshold of unit $i$, and $w_{i j}$ is the connection weight between units $x_{i}$ and $x_{j}$, these two variables are bounded value.

So, the energy function is a bounded function. That is to say, the energy function can lead the final state into a stable state, if the network updating can satisfy the condition:

$$
\square E=E(t+1)-E(t) \leq 0
$$

The energy of the network will decline by iteration, and the network can converge to a minimum from any initial state. In this condition, we can get the output of the network. 


\section{Solution Spproach}

The proposed framework for evaluation of service quality of public transit includes three steps.

Step 1: To develop an ideal service quality evaluation index system of public transit. Moreover, design a questionnaire for collecting data for measuring service quality of public transit.

Step2: To evaluate the service quality of public transit with DHNN.

Step3: Evaluation and analysis of the calculation results.

\subsection{Service quality evaluation index}

Service quality of public transit is characterized by many aspects, and therefore a number of attributes should be considered in order to capture passenger perceptions about the quality level of supplied services. Some previous studies showed that people interviewed can have some difficulties in making a choice among subjective preference options [16]. In the case, the value of the level for a certain attribute is natural number scale from 0 to 100 . Thus, based on the earlier pilot study $[3,4,11,13,15]$ and the data needs of the DHNN, we concluded that 11 attributes describe the major dimensions of service quality from a traveler's perspective. Moreover, the classificatory attributes inclade the level seleeted as the references are shown in Table 1.

The attributes analyzed in Table 1 could be explained as follows: 'Availability' represents how easily passengers can access and use public transit service from bus stop. It determines whether or not the public transit could be selected as a potential traffic mode. 'Frequency' determines the number of public transit an hour passengers could choose. Service frequency also measures the convenience of public transit service to choice passengers. 'Reliability' means how often public transit service is provided to passengers when promised. 'Efficiency' illustrates the time consumption of public transit than other travel mode. 'Accessibility' measures the ability or ease of all passengers to travel among various origins and destinations with public transit. 'Crowdifg') represents the space occupancy of the public transit vehicle. 'Cleanliness' illustrates the amount of litter; exterior dirt conditions; floor and seat cleanliness; graffiti; and window condition and so on. 'Security' covers both the real and perceived chance of beng the victim of a crime while using public transit. The testing results reflect the probability of being the victim of a crime while taking public transit. 'Fare' is the required payment for a passenger using public transit vehicle. 'Information' is the availability of service information (maps, timetable, delays, weather, etc.) could afford to passengers by phone, internet, and variable information boards and so on.

Table 1. Service quality evaluation index

\begin{tabular}{ccccccc}
\hline No. & Attributes & Level 1 & Level 2 & Level 3 & Level 4 & Level 5 \\
\hline 1 & Availability & $80-100$ & $60-80$ & $40-60$ & $20-40$ & $0-20$ \\
2 & Frequency & $80-100$ & $60-80$ & $40-60$ & $20-40$ & $0-20$ \\
3 & Reliability & $80-100$ & $60-80$ & $40-60$ & $20-40$ & $0-20$ \\
4 & Efficiency & $80-100$ & $60-80$ & $40-60$ & $20-40$ & $0-20$ \\
5 & Accessibility & $80-100$ & $60-80$ & $40-60$ & $20-40$ & $0-20$ \\
6 & Crowding & $80-100$ & $60-80$ & $40-60$ & $20-40$ & $0-20$ \\
7 & Cleanliness & $80-100$ & $60-80$ & $40-60$ & $20-40$ & $0-20$ \\
8 & Driver's attitude & $80-100$ & $60-80$ & $40-60$ & $20-40$ & $0-20$ \\
9 & Security & $80-100$ & $60-80$ & $40-60$ & $20-40$ & $0-20$ \\
10 & Fare & $80-100$ & $60-80$ & $40-60$ & $20-40$ & $0-20$ \\
11 & Information & $80-100$ & $60-80$ & $40-60$ & $20-40$ & $0-20$ \\
\hline
\end{tabular}




\subsection{Questionnaire Design}

The questionnaire listed below was adopted in order to collect the reasonable statistic results on the basis of the service quality calculation model. The questionnaires were distributed among customers on board from 8 Oct to 15 Oct 2012.

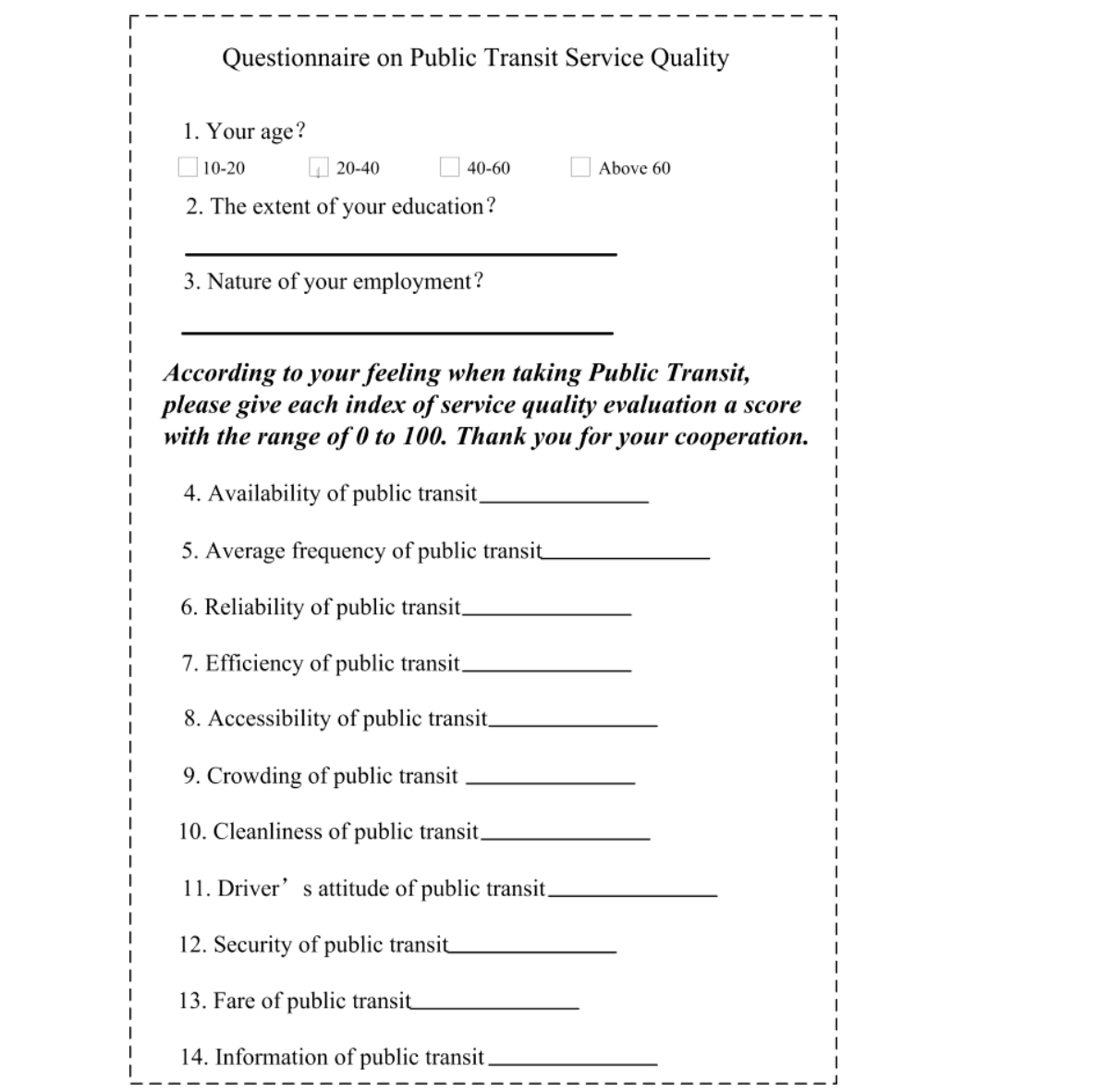

Figure 2. Questionnaire on public transit service quality

\section{Model application}

\subsection{Data collection}

The survey, as a support to the study, was conducted in the winter of 2012 from Oct 8 to Oct 15 in the city of Nanjing. The questionnaires were filled out by face to face interviews among the customers on board. The sample for this study consists of 680 customers from 5 bus routes chosen at random. The public transit in this city is composed of 6000 buses and 400 transit lines which provide services to $30 \%$ of its residents every day. Descriptive statistics of the survey data are illustrated in Table 2. 
Table 2. Descriptive statistics of the survey data

\begin{tabular}{cccccccccccc}
\hline \multirow{2}{*}{ No. } & \multirow{2}{*}{ Attributes } & \multicolumn{2}{c}{ Bus Route 1 } & \multicolumn{3}{c}{ Bus Route 2 } & \multicolumn{2}{c}{ Bus Route 3 } & \multicolumn{2}{c}{ Bus Route 4 } & \multicolumn{3}{c}{ Bus Route 5 } \\
& & Mean & Var & Mean & Var & Mean & Var & Mean & Var & Mean & Var \\
\hline 1 & Availability & 73 & 7.17 & 46 & 8.72 & 38 & 9.77 & 26 & 5.09 & 58 & 9.93 \\
2 & Frequency & 88 & 5.63 & 72 & 4.20 & 47 & 7.21 & 32 & 5.61 & 47 & 7.03 \\
3 & Reliability & 66 & 7.04 & 63 & 7.59 & 42 & 3.74 & 25 & 3.49 & 51 & 9.33 \\
4 & Efficiency & 72 & 6.12 & 67 & 9.83 & 53 & 4.69 & 27 & 5.04 & 25 & 4.97 \\
5 & Accessibility & 62 & 6.30 & 74 & 7.75 & 65 & 6.06 & 35 & 5.32 & 62 & 4.19 \\
6 & Crowding & 37 & 8.42 & 49 & 3.37 & 54 & 5.33 & 89 & 3.26 & 44 & 8.80 \\
7 & Cleanliness & 53 & 4.81 & 34 & 8.12 & 38 & 7.08 & 76 & 4.62 & 16 & 4.43 \\
8 & Driver's attitude & 47 & 4.01 & 37 & 7.29 & 65 & 8.28 & 84 & 4.33 & 55 & 3.31 \\
9 & Security & 75 & 7.74 & 69 & 3.50 & 44 & 9.84 & 76 & 6.95 & 84 & 4.37 \\
10 & Fare & 68 & 9.24 & 71 & 4.12 & 44 & 7.96 & 67 & 7.86 & 56 & 4.39 \\
11 & Information & 32 & 2.20 & 41 & 2.47 & 38 & 3.67 & 35 & 2.31 & 37 & 2.81 \\
\hline
\end{tabular}

The evaluation result of 5 bus routes chosen at random frøm Nanjing with DHNN is shown in Figure 3.

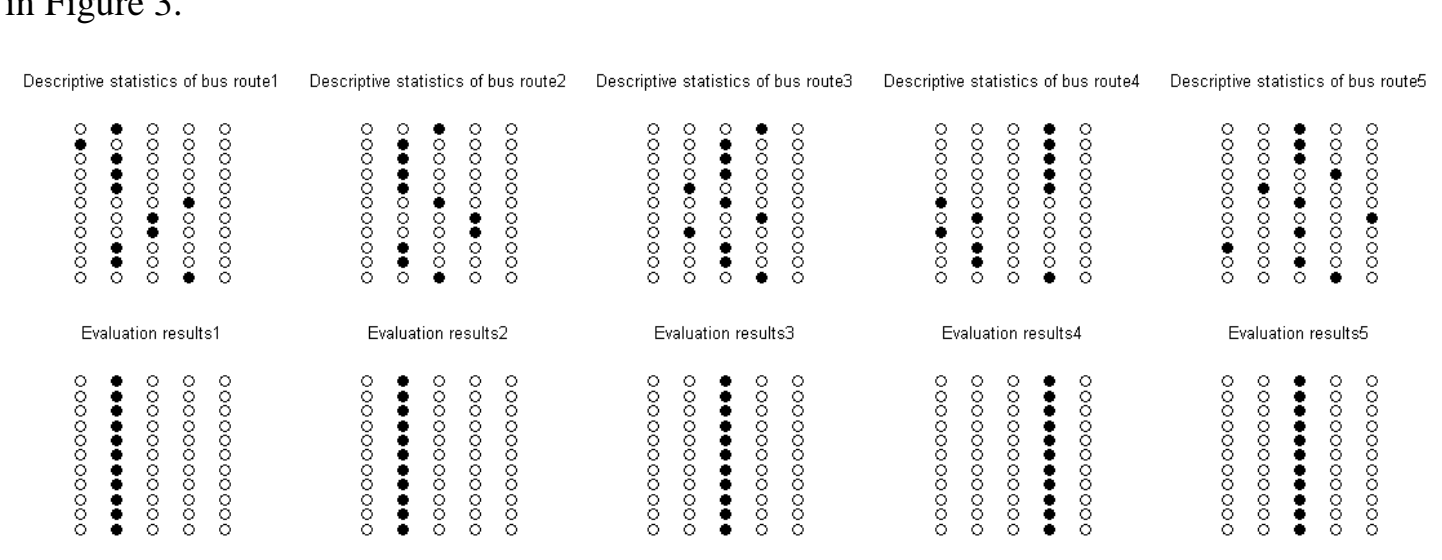

Figure 3. Evaluation result of 5 bus routes

According to the results of the evaluation in Figure 3, the service quality of Nanjing public transit coul be expected to exceed the average level on the whole. But different bus route really shows the significant differentiation. In general, the travel demand of passengers in Nanjing remains in a fundamental state, that is, they would put forward higher requirements for frequency, reliability and accessibility of public transit and be more patient with several comfort indexes, such as crowing, cleanliness and so on. In addition, the recognition of these passengers on public transport information is still at a very low level.

\section{Conclusion}

The main purpose of this paper is to provide us with a more efficient and effective method that could conduct a full assessment of service quality among different bus lines. Service quality of public transit is characterized by many aspects. So, considering the particularity and complexity of those evaluation indexes, in this paper, Discrete Hopfield Neural Networks (DHNN) is selected to analyze service quality of public transit. 
The validity of the proposed methodology has been confirmed by the experimental results of 5 bus routes chosen at random in Nanjing. Through setting up systematic model and data test, the paper points out that it is essential to command over more detailed information and knowledge about service quality of public transit from passenger perceptions with DHNN.

Last but not least, the methodology we supposed in this paper will contribute a lot to practical application of DHNN. In fact, when standing in passenger's place, the model will be identified as a valuable tool for planners and transit operators if they have to measure service quality and evaluate the importance of the various service quality aspects.

\section{Acknowledgments}

This research was supported by a grant from the 2013 Scientific Research and Innopation Project for Postgraduates in Jiangsu Province (Grant No. CXZZ13_0121). The authors appreciate the support from Southeast University and all the voluntary respondents.

\section{References}

[1] L. J. Davison and R. D. Knowles, "Bus quality partnerships, modal shirt and traffic decongestion", JOURNAL OF TRANSPORT GEOGRAPHY, vol. 14,(2006), pp. 177-194,

[2] T. T. Deng and J. D. Nelson, "The perception of Bus Rapid Transit: a passenger survey from Beijing Southern Axis BRT Line 1", TRANSPORTATIONPLANNING AND TECHNOLOGY, vol. 35, (2012), pp. 201-219.

[3] D. A. Hensher, P. Stopher and P. Bullock, "Service quality developing a service quality index in the provision of commercial bus con(radt", TRANSPORTATION RESEARCH PART A-POLICY AND PRACTICE, vol. 37, (2003), pp. 499-517.

[4] K. Associates, U.S.F.T. Administration, T.C.R. Program, and T.D. Corporation, "Transit Capacity and Quality of Service Manual", Transportation Research-Board National Research, (2003).

[5] A. Nkurunziza, M. Zuidgeest, M Brussel and F. Van den Bosch, "Spatial variation of transit service quality preferences in Dar-es-Salaam", JOURNAL OE TRANSPORT GEOGRAPHY, vol. 24, (2012), pp. 12-21.

[6] D. Susniene, "Quality Approach to the Sustainability of Public Transport", TRANSPORT, vol. 27, (2012), pp. $102-110$.

[7] J. Paquette, F. Bellavance, J. F. Cordeau and G. Laporte, "Measuring quality of service in dial-a-ride operations: the case of a Canadian city", TRANSPORTATION, vol. 39, (2012), pp. 539-564.

[8] L. Redman, M. Friman, T. Garling and T. Hartig, "Quality attributes of public transport that attract car users: A research review", TRANSPORT POLICY, vol. 25, (2013), pp. 119-127.

[9] M. Friman, "Implementing quality improvements in public transport", Journal of Public Transportation, vol. 7, (2004).

[10] Z. Mei, D. Wang, F. Wang, J. Chen and W. Wang, "Research on the Multiroute Probit-Based Public Transit Assignment Model Based on Bus Stop", Mathematical Problems in Engineering, vol. 2012, (2012).

[11] M. Cantwell, B. Caulfield and M. O Mahony, "Examining the factors that impact public transport commuting satisfaction". Journal of Public Transportation, vol. 12, (2009), pp. 1-21.

[12] S.Fil poyic, S. Tica, P. Zivanovic and B. Milovanovic, "Comparative Analysis of the Basic Features of the Expected and Perceived Quality of Mass Passenger Public Transport Service in Belgrade", TRANSPORT, vol 24, (2009), pp. 265-273.

[13] L. Eboli and G. Mazzulla, "A new customer satisfaction index for evaluating transit service quality", Journal of Public Transportation, vol. 12, (2009), pp. 21-37.

[14] D. A. Hensher, C. Mulley and N. Yahya, "Passenger experience with quality-enhanced bus service: the tyne and wear 'superoute' services", TRANSPORTATION, vol. 37, (2010), pp. 239-256.

[15] L. Dell'Olio, A. Ibeas and P. Cecin, "Modelling user perception of bus transit quality", TRANSPORT POLICY, vol. 17, (2010), pp. 388-397.

[16] L. Eboli and G. Mazzulla, "How to Capture the Passengers' Point of View on a Transit Service through Rating and Choice Options", TRANSPORT REVIEWS, vol. 30, (2010), pp. 435-450.

[17] F. Des Rosiers, M. Theriault, M. Voisin and J. Dube, "Does an Improved Urban Bus Service Affect House Values?", INTERNATIONAL JOURNAL OF SUSTAINABLE TRANSPORTATION, vol. 4, (2010), pp. 321-346.

[18] C. Cirillo, L. Eboli and G. Mazzulla, "On the Asymmetric User Perception of Transit Service Quality", INTERNATIONAL JOURNAL OF SUSTAINABLE TRANSPORTATION, vol. 5, (2011), pp. 216-232. 
[19] J. P. Zhou and L. Schweitzer, "Getting Drivers to Switch: Transit Price and Service Quality among Commuters", JOURNAL OF URBAN PLANNING AND DEVELOPMENT-ASCE, vol. 137, (2011), pp. 477-483.

[20] W. T. Lai and C. F. Chen, "Behavioral intentions of public transit passengers-The roles of service quality, perceived value, satisfaction and involvement", TRANSPORT POLICY, vol. 18, (2011), pp. 318-325.

[21] L. Eboli and G. Mazzulla, "A methodology for evaluating transit service quality based on subjective and objective measures from the passenger's point of view", TRANSPORT POLICY, vol. 18, (2011), pp. $172-181$.

[22] N. Sharaby and Y. Shiftan, "The impact of fare integration on travel behavior and transit ridership", TRANSPORT POLICY, vol. 21, (2012), pp. 63-70.

[23] M. Rojo, H. Gonzalo-Orden, L. Dell'Olio and A. Ibeas, "Relationship between service quality and demand for inter-urban buses", TRANSPORTATION RESEARCH PART A-POLICY AND PRACTICE, voł. 46, (2012), pp. 1716-1729.

[24] J. de Ona, R. de Ona and F. J. Calvo, "A classification tree approach to identify key factors oftransit service quality", EXPERT SYSTEMS WITH APPLICATIONS, vol. 39, (2012), pp. 11164-11171.

[25] J. J. Hopfield, "Neural networks and physical systems with emergent collective computational abilities",. Proceedings of the national academy of sciences, vol. 79, (1982), pp. 2554-2558.

[26] L. Wan, Q. H. Zhou, Z. G. Zhou and P. Wang, "Dynamical Behaviors of the Stochastic Hopfield Neural Networks with Mixed Time Delays", ABSTRACT AND APPLIED ANALYSIS, (2013).

[27] J. Li, Y. F. Diao, M. D. Li and X. Yin, "Stability Analysis of Discrete Hopfield Neural Networks with the Nonnegative Definite Monotone Increasing Weight Function Matrix DISCRETE DYNAMICS IN NATURE AND SOCIETY, (2009).

[28] U. Wen, K. Lan and H. Shih, "A review of Hopfield neural networks for solving mathematical programming problems", European Journal of Operational Research vol. 198, (2009)pp. 675--687.

[29] R. U. L. Rojas, "Neural networks: a systematia introduction", Springer, (1996).
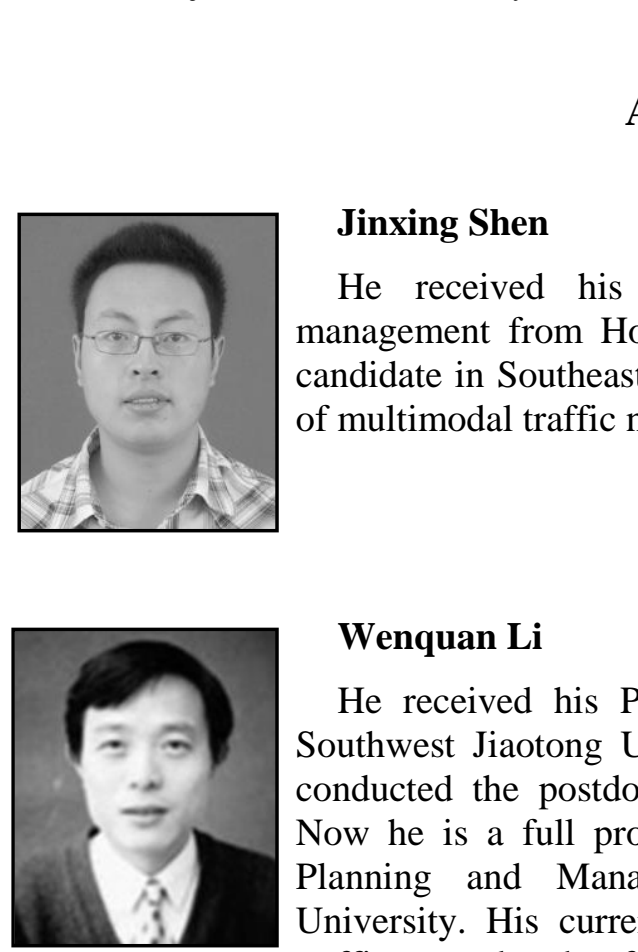

Authors

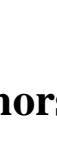

\section{Jinxing Shen}

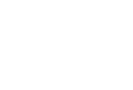

He received his MS degree in Transportation planning and management from Hohai University in 2009. He is currently a Ph.D. candidate in Southeast University. His research interests are in the areas of multinodal traffic network and information systems.

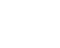

\section{Wenquan Li}

He received his $\mathrm{PhD}$ in Transportation Management (1997) from Southwest Jiaotong University of China. From 1997 to 1999, he had conducted the postdoctral research in Southeast University of China. Now he is a full professor and doctoral supervisor of Transportation Planning and Management at Transportation College, Southeast University. His current research interests include different aspects of traffic control and traffic flow theory. 
International Journal of Multimedia and Ubiquitous Engineering

Vol.9, No.2 (2014)

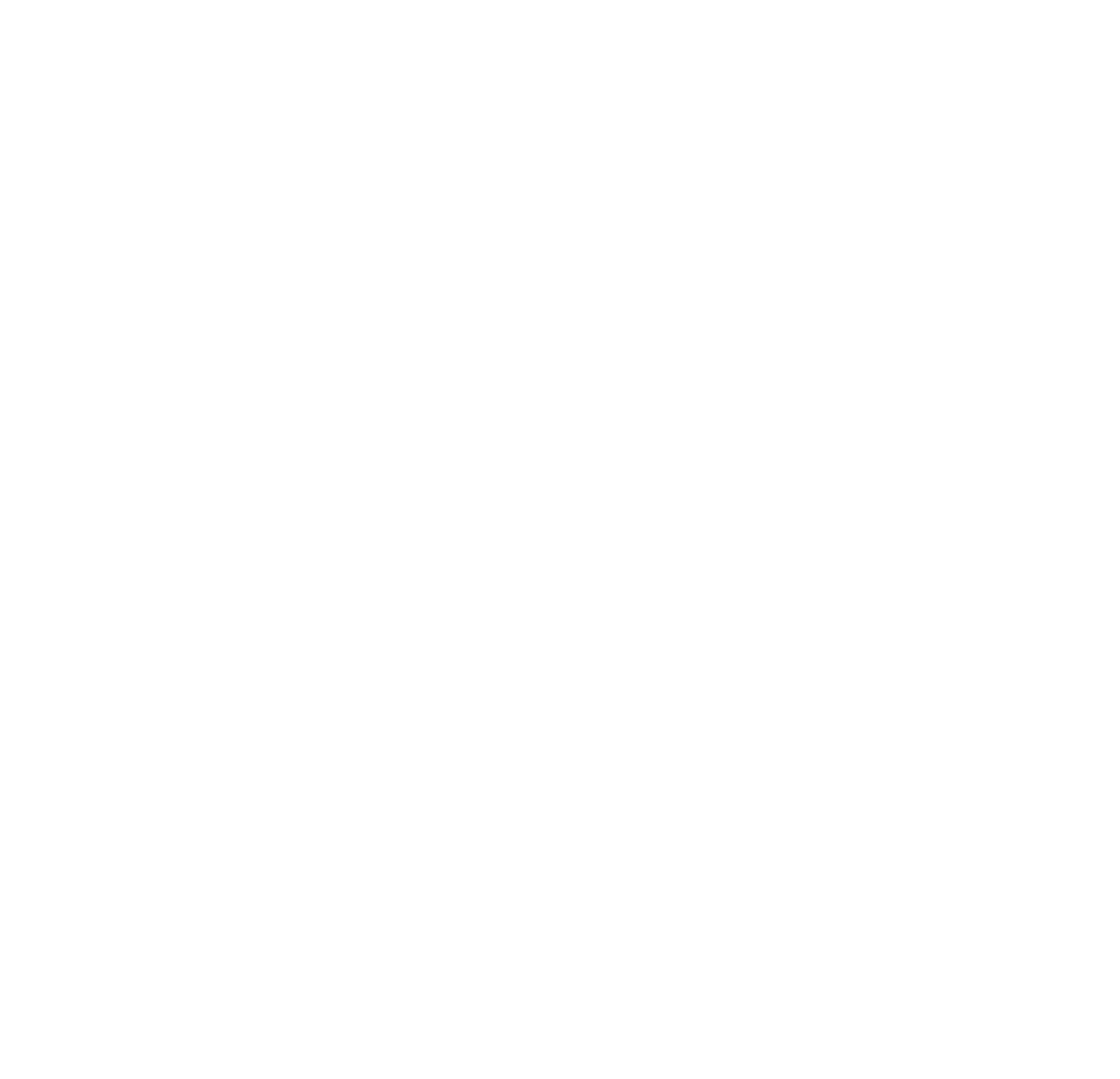

